\title{
Preparation of Phased and Merged Safety Analysis Reports for New DOE Nuclear Facilities
}

Prepared for the U.S. Department of Energy Assistant Secretary for Environmental Management

Project Hanford Management Contractor for the

U.S. Department of Energy under Contract DE-AC06-96RL13200

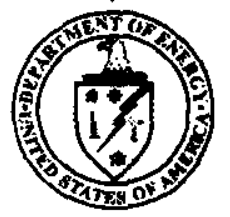

Richland, Washington 99352

\section{Copyright Licenee}

By acceptence of this article, the publisher and/or recipient acknowledges the U.S. Government's right to retain a nonexclusive, royalty-free license in and to any copyright covering this paper. 


\section{INFORMATION CLEARANCE FORM}

\begin{tabular}{|ll}
\hline \multicolumn{2}{|c|}{ A. Information Category } \\
$\square$ Abstract & $\square$ Journal Article \\
$\square$ Summary & $\square$ Internet \\
$\square$ Visual Aid & $\square$ Sotware \\
$\square$ Full Paper & $\square$ Report \\
$\square$ Other
\end{tabular}

B. Docurnent Number DOE -0283

Preparation of Phased and Meged Jafete Analuses Reports for New Doe Nuclear Facilities

E. Requlred information

D. Internet Address guy_e_ii __buhop@re.gav

1. Is document potentially Classified? $\square$ No $\square$ Yes (MANDATORY)

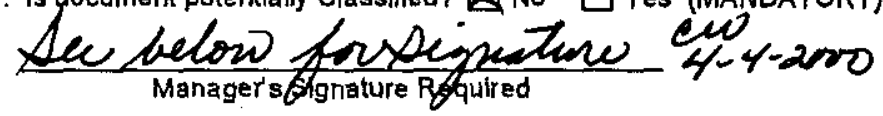

If Yes ADC Signature Required

2. Internal Roview Required? if Yes, Document Signatures Below $\square$ No $\square$ Yes Classified Counsel Program No $\square$ Yes

3. References in the Information are Applled Technology $\mathbb{N} \square$ Yos Export Controlled Information DNo $\square$ Yes
4. Does Information Contain the Following: (MANDATORY)

a. New or Novel (Patentable) Subject Matter? $\triangle$ No $\square$ Yos If "Yos". Dlsclosure No.:

b. Information Received in Confidence, Such as Propriatary and/or Invantions? 4No $\square$ Yes If "Yos", Affix Appropriate Legends/Notices.

c. Copyrights? $\square$ No $\square$ Yes If "Yes", Attach Pormission.

d. Trademarks? 8 No $\square$ Yes If "Yes", Identlfy in Document.

5. Is Information requiring submission to OSTI? $\square$ No $\square$ Yes

If Yes UC-_ and $B \& R$ -

6. Release Level? 8 Public $\square$ Limited

7. Charge Code

\section{F. Complete for a Journal Article}

1. Title of Journal G. Complete for a Presentation

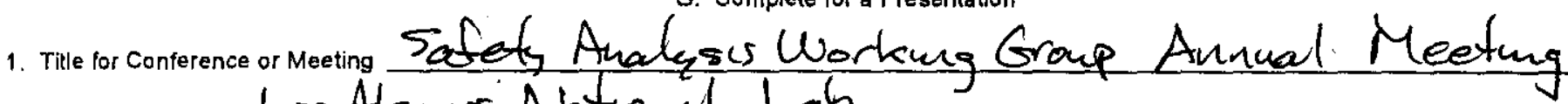
2. Group sponsoring Los Alamos Natwonal Lab

3. Date of Conference $\operatorname{May} 2-4,2000$ 4. city/state Santare, N. M.

5. Will Information be Published in Proceedings? ZhNo 4 Yes 7 G/Wil Material be Handed Out? $\square$ No 8 Yes

H. Aythor/Requestor

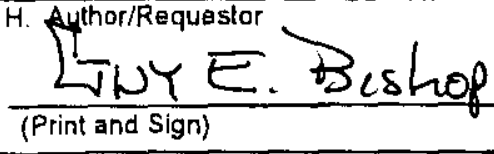

I. Reviewers

General Counsel Yes Pint

Office of External Affairs

DOE-RL

other ABD Dr Pint
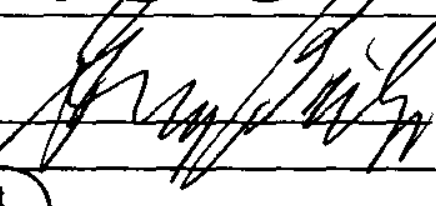
Responsible Manager

Other

$\square$

$\square$

可

C. SBOSin

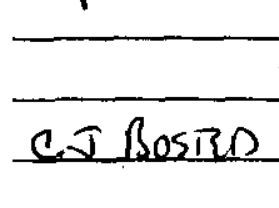

(Print and Sign)

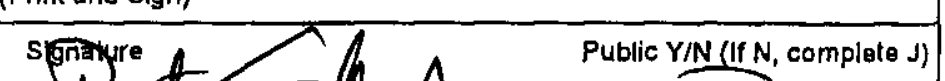

Analęses

J. If Informaton includes Sensitive information and is not to be released to the Public Indicate category below. Information Clearance Agproval.
$\square$ Applied Technology $\square$ Protected CRADA
$\square$ Personal/Private $\square$ Export Controlled
$\square$ Proprietary $\square$ Procurement-Sensittve
$\square$ Business-Sensitive $\square$ Patentable
$\square$ Predecisional $\square$ other (Specify)
$\square$ UCNI
K. If Additional Comments, Please Attach Separate Sheet 


\section{Preparation of Phased and Merged Safety Analysis Reports for New DOE Nuclear Facilities}

G.E. Bishop

U.S. Department of Energy, Richland, WA

Date Published

May 2000

To Be Presented at

Safoty Analysis Working Group Annual Mosting

Los Alamos National Lab

Santa Fo, N.M.

May 2, 2000

Prepared for the U.S. Department of Energy

Assistant Secretary for Environmental Management

Project Hanford Management Contractor for the

U.S. Department of Energy under Contract DE-AC06-96RL13200

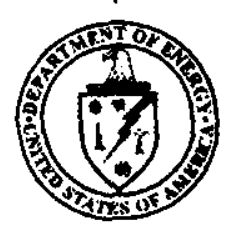

United States

Department of Energy

P.0. Box 550

Richland, Washington 99352

Copyright Licanse

By acceptance of this article, the publisher and/or recipient acknowledges the U.S. Government's right to retain a nonexclusive, royelty-free license in and to any copyright covering this paper.

Ghistine Millingtemo 4u4-2000 


\section{LEGAL DISCLAIMER}

This report was prepared as an account of work sponsored by an agency of the United States Government. Netther the

United States Government nor any agency thereof, nor any of their employees, nor any of their contractors, subcontractors or their employees, makes any warranty, express or implied, or assumes any logal liability or reeponsibilty for the accuracy, completeness, or any third party's use or the results of such use of any information, apparatus, product, or process disclosed, or represents that its use would not infringe privately owned rights. Reference herein to any specific commercial product, process, or senvice by trade name, trademark, manufacturer, or otherwise, does not neceasarily constitute or imply its endorsement, recommendation, or favoring by the United States Government or any agency thereof or its contractors or subcontractors. The views and opinions of authors expressed herein do not necessarily state or reflect those of the United States Government or any agency thereof.

This report has been reproduced from the begt available copy. Available in paper copy and microfiche.

Avallable electronically at http://uww.doe.gov/bridge. Available for a proceseing fee to the U.S. Department of Energy and its contractors, in paper, from:

U.S. Department of Energy

Orfice of Scientific and Tochnical Information

P.O. Box 62

Oak Ridge, TN 37831-0062

phone: 865-576-8401

fax: 865-576-5728

email: reports_adonis.osti.gov(423) 576-8401

Printed in the United States of America 


\title{
Preparation of Phased and Merged Safety Analys is Reports \\ for New DOE Nuclear Facilities
}

\author{
Guy E. Bishop. III
}

Department of Energy. Richland Field Office, Richland, Wa. 509-372-1856

$$
\text { guy_e_iii_bishoparl.gov }
$$

\section{Abstract:}

The Spent Nuclear Fuels Project (SNFP) is charged with moving to storage 2.100 metric tons of spent nuclear fuel elements left over from plutonium production at DOE's Hanford site in Washington state. Two new facilities,- the Cold Vacuum Drying Facility (CVDF) and the Canister Storage Building (CSB) are in final construction. In order to meet aggressive schedule commitments, the SNFP chose to prepare the safety analysis reports (SAR's) in phases that covered only specific portions of each facility's design as it was built. Each SAR also merged the preliminary and final safety analysis reports into a. single SAR, thereby covering all aspects of design, construction, and operation for that portion (phase) of the facility. A policy of "NRC equivalency" was also implemented in parallel with this effort. with the goal of achieving a rigor of safety analysis equivalent to that of NRC-licensed fuel processing facilities.

DOE Order 5480.23. "Nuclear Safety Analys is Reports" allows preparation of both a phased and a merged SAR to accelerate construction schedules. - However, project managers must be aware that such acceleration is not guaranteed. Managers considering this approach for their project should be cognizant of numerous obstacles that will be encountered. Merging and phasing SAR's will create new, unique, and unanticipated difficulties which may actually slow construction unless expeditiously and correctly managed. Pitfalls to be avoided and good practices to be implemented in preparing 
phased and merged SAR's are presented. The value of applying NRC requirements to the DOE safety analysis process is also discussed. As of December, 1999. the SNFP has completed and approved a SAR for the CVDF. Approval of the SAR for the CSB is pending.

\section{Background:}

The Department of Energy relies upon a safety analysis report (SAR) to document the adequacy of a nuclear facility's safety basis which provides assurance that the facility can be constructed, operated, maintained, and shutdown safely and in compliance to applicable laws and regulations. DOE Order 5480.23. "Nuclear Safety Analysis Reports", prescribes two types of SAR's for a facility: a Preliminary Safety Analysis Report (PSAR), and Final Safety Analysis Report (FSAR). A PSAR, prepared at the start of a facjlity's construction, demonstrates that a facility can be built safely. An FSAR, prepared at the conclusion of construction. demonstrates that a facility can be operated safely. The two types of SAR's thus perform fundamentally different functions. The PSAR serves as the safety basis for DOE's decision to authorize facility design, procurement, construction, and pre-operational testing. The FSAR serves as the safety basis for DOE's decision to authorize facility operation. Both kinds of SAR's are a risk management tool. One measures the risk of design and construction, the other of operation. ${ }^{1}$

1. PSAR's must also show that the facility could be operated. maintained, and shutdown safely. (Otherwise, why build the facility in the first place?) However. the PSAR focuses on design and construction: its analysis of operation is typically summary-level and lacks specifics. The FSAR analysis is fully developed, refined, detailed, and most of all, final. 
Because preparation of a PSAR followed later by an FSAR can require extensive time and resources. DOE allows (by direction of the PSO) preparation of a merged PSAR/FSAR for a facility. Such a SAR performs in one document the roles of both the PSAR and FSAR and therefore must contain the kinds of information contained in each. The intent is to save project resources--time and money. The single SAR is approved prior to operation. ${ }^{2}$

DOE also allows (by direction of the PSO) that the PSAR. FSAR, both, or the merged PSAR/FSAR be completed in stages. In such cases, review and approval of the facility's safety basis is done in phases (stages) which are best coordinated to completion of specific milestones (decision points, steps. portions) of facility construction. Each successive phase of the SAR must carry forward (by direct incorporation or reference) the safety analyses of all preceding SAR phases so that the current approved SAR covers all design. construction, and operational considerations, commitments, and conditions up to that point in the facility's construction. DOE must approve the contractor's program to resolve nonconformances to the phased SAR and his method to identify challenges to the safety bases of the previously approved phases. ${ }^{3}$

Note that neither the merged nor phased SAR concept is necessarily linked to "fast-track" facility construction. Fast-track is a management option in which normally sequential activities (eg. design first. procurement

2. It could be argued that the logical interpretation of paragraph 9.a.(3) of DOE Order 5480.23 that allows for a merged SAR would be to submit the merged PSAR/FSAR at the start of construction, not its conclusion. However, the Order specifically states "a single FSAR" thus implying the submission comes at the end. Logistically. it is virtually impossible for a contractor to submit a merged SAR at the beginning of a project.

3. $\quad$ See DOE Order 5480.23. Attachment 1. paragraph 4.f.(8).(c).3. 
Preparation of Phased and Merged SAR's for New DOE Nuclear Facilities second) are done in parallel to save schedule. A project managed as fast-track does not have to use merged or phased SAR's, nor is a project employing merged or phased SAR's necessarily then fast-track.

\section{Theory of Benefit of Merged and Phased SAR's:}

The primary purpose of preparing a merged or phased SAR for a project is to save time--ie, accelerate facility completion by compressing the schedule. Saving time will, theoretically, save money as well.

\section{Merged SAR's:}

The benefit of using a merged SAR rests on the premise that it is easier to write a single (albeit thicker) SAR in a single concentrated effort than it is to write two SAR's widely spread apart in time. Such being the case. project schedule can be accelerated and funds could thereby be saved. Theoretically, such an idea (one-step SAR approval) is sound.

Figure One illustrates the merged SAR. Notice the balance that determines if preparing a merged SAR will accelerate or delay a project. To the plus, a merged PSAR/FSAR saves one early DOE review and approval cycle. allowing the construction to start (and finish) sooner. To the negative. the work scope of a merged SAR is greater than either a PSAR or FSAR alone. In addition, review of a merged SAR takes longer than either PSAR or FSAR alone. These two negatives may completely counter the positive savings of one review cycle. However, there is yet a third negative contributor that also must be considered. 
The greatest unknown risk at the start of the project when the decision to merge is made is the amount of rework that will be needed for errors subsequently found in the merged SAR. This is shown as $T_{\text {Rework }}$ on Figure One. This time is not known but. as shown in Figure One, is the greatest single influence on the over-all outcome. Notice also that if time is not saved between conventional SAR preparation and a merged SAR preparation (ie, the time to prepare and approve a merged SAR is the same as the total time needed to prepare and approve a PSAR and an FSAR), then any time spent in rework delays the project. ${ }^{4}$ The manager must balance the time saved by eliminating one (PSAR) review cycle against the time lost to prepare and review a bigger SAR coupled with the estimated time to recover any deficiencies in that analysis. A project manager must decide to which side the respective scales are likely to tip before pursuing merged SAR's.

The manager must consider the risks, in terms of rework or backfits. that a deficient SAR presents to the project. The great risk is that the facility will be unsafe due to incorrect codes and standards or selection of safety equipment, which will require long and expensive upgrade or redesign. The merged SAR thus presents a risk of "looking backward" at the completed facility and finding that its safety analysis is in serious error and its design is faulty.

In choosing a merged SAR, DOE relinquishes its means to review a facility's safety basis (via the PSAR) prior to start of construction. This

4 What this means to the project manager is that there is a "delta" between the conventional and merged SAR preparation/approval times below which a merged SAR should not be considered. For example. if only 4 days were saved using a merged SAR, it is reasonable to expect at least four days of rework for a moderately complex facility. A merged SAR would delay that project. 
is the primary disadvantage of merged SAR's. DOE gives up the crucial feature to review construction work before it is done which ensures that the facility will be safe to operate. Instead. DOE is presented with a finished facility and a finished SAR. In agreeing to a merged SAR, DOE gambles that the facility will be completed more quickly. The implicit assumption is that the contractor will deliver a quality safety analysis. In accepting a merged format. DOE thus risks that no major deficiencies will be found with the SAR. If the SAR has no significant errors, the gamble has paid off and the project will be completed ahead of a traditional PSAR/FSAR schedule.

The resultant savings cannot be easily predicted. They depend on many site-specific factors such as the project's complexity, magnitude of its hazards (which drive the rigor of the safety analysis), and the actual quality of the SAR prepared by the contractor which affects the review time needed for it.

However, if the SAR has serious omissions (or the facility was not built to its standards), DOE is faced with either expensive backfits to correct the deficiencies or accepting a higher risk of operation than it had intended. The time needed for backfits is $T_{\text {Rework }}$ in Figure One. The risk is real. DOE facilities have been found unsafe to operate after completion of construction. ${ }^{5}$ The time needed to correct these deficiencies eats into the time savings of having a merged SAR and, if excessive. will delay the project. In this case, the gamble was lost.

5. $\quad$ For example, a facility was built at the Los Alamos site to store plutonium in the early $1990^{\circ} \mathrm{s}$ that subsequently could not be used for that purpose due to inadequate design and safety considerations. 


\section{Time is the Factor:}

What must be considered in deciding to use a merged SAR is the impact on project time, not project cost. A project manager should not expect a merged SAR to cut project costs by reducing expenditure for safety analysis. The central objective should be to save time, not safety analysis money. A project's labor cost budgeted at $\$ 100 \mathrm{million} /$ year spends $\$ 400.000 /$ day . Saving three days of schedule theoretically saves $\$ 1,200,000$. These kinds of savings generally dwarf any savings, or additional expenditure, for safety analysis.

The manager should also recognize that the expenditure for safety analysis may actually be higher, due to the more intensive review given a merged SAR, than for the conventional PSAR/FSAR. Again, any dollar savings for the project come from acceleration of the schedule.

\section{Success Factors:}

Success factors for using a merged SAR can be identified. Preparing a merged SAR for a project will likely be successful if DOE is certain that:

1. the $A / E$ also prepares the safety analysis:

2. all project requirements have been clearly identified before start of design and are smoothly passed down through management and engineering levels to the construction crews in the field.

3. the contractor has excellent safety analysis skills in which DOE has full confidence based on historical experience. 
Conclusion:

In the present DOE environment, a merged SAR appears best suited for small. relatively simple facjlities involving low to moderate radiological and toxicological hazards. A merged SAR will not necessarily save time or money.

\section{Phased SAR's:}

The risks assumed by DOE with a merged SAR can be partially mitigated by using another unconventional SAR development method, the phased SAR. A phased SAR can be applied to a PSAR and/or an FSAR, or to a merged SAR. A phased SAR completes blocks of the SAR timed to construction milestones (decision points).

Figure Two illustrates the phased SAR. SAR approval for each successive construction phase should be obtained prior to commencement of the next phase of work. Because of the series nature of these approvals, delay in timely approval of the next SAR phase can cause a day-for-day slip in the start of the next (critical-path) phase of construction work. To minimize the risk of delaying construction. SAR preparation and approval must be moved off of critical path, as shown in the first and third phases.

Notice the crucial shift of the completion of each succeeding phase of the safety analysis away from the critical path (construction work) by starting the next phase early. Preparation of the next phase of the SAR must occur while the construction work for the previous phase is on-going. Minimal overlap of safety analysis onto the construction critical path then occurs. This overlap. the time between the end of the last construction phase and approval of the next phase's SAR, is called $\Delta T_{\phi}$ in Figure Two. Overlap of SAR review/approval onto critical path. $\Delta T_{\phi}$, must be held to a minimum. Ideally. 
$\Delta T_{\phi}$ is zero as shown in the first and third phases. (Phase two is reality.) This is essential for a phased SAR to accelerate the project schedule. The longer that approval (or, even worse, approval and preparation) of the SAR phases overlaps onto critical path. the less likely is a phased SAR to accelerate the project's schedule. ${ }^{6}$

Design changes made following approval of the applicable SAR phase that affect that phase are a great risk to phased SAR preparation. DOE has no clear mechanism for formally dealing with such changes. ${ }^{7}$ Aggravating this risk is the inherently myopic nature of a phased SAR. Because the SAR is in blocks (phases) it is impossible until the final completed SAR is received to see or understand the facility's integrated safety basis. With phased SAR's, the over-all picture remains hazy until the end. Thus, the risk in phased SAR's is looking forward in time toward what the finished facility will be and describing that adequately in the blocks of SAR's leading to the completed SAR. (Contrast the phased SAR to a merged SAR which looks backward at what the facility is.)

The other great concern is tracking assumptions and commitments made to approve one SAR phase into the successive phases. The contractor is required to track these assumptions as design commitments and show how subsequent SAR

6 - Thus, if the schedule shows that the safety analysis work is almost entirely critical path, the phased SAR will delay project completion and a phased SAR should not be considered.

7. The reader may believe that such issues can be handled via the unreviewed safety question process (DOE Order 5480.21). Such is not the case. Most facilities do not implement the USQ process until after operation. Even if it were implemented during construction, the existing (phased) SAR may not be complete enough to properly screen a design change as a USQ. anyway. 
phases meet the commitments. ${ }^{8}$ An exemplary configuration management program is essential to mitigate both of these risks--design changes and commitment tracking.

Also notice that another factor complicates the decision to use a phased SAR and can affect the critical path. Work in the field can be delayed by poor coordination of construction work around the SAR approved phases. Field work can only by done on those portions of the facility that have approved SAR's. A lag can be introduced, shown as $T_{\text {Gap }}$ on Figure Two, when the next construction phase is delayed by field conditions (eg, not having the right work crews ready to work) that delay the next construction phase beyond the built-in delay of awaiting approval of the next phase of the SAR. Minimizing $T_{\text {Gap }}$ requires an experienced contractor adroit at shuffing and coordinating work crews.

In practice, each phase of the SAR must be completed, reviewed and approved by the time the decision is made to proceed to the next phase of construction. The completed SAR covers only that applicable portion of the facility and nothing else. The SAR need not have all chapters of a complete SAR, either. ${ }^{9}$ It must have the applicable description (in detail comparable to either a PSAR- or FSAR-level or both) of that portion of the facility, the hazard and accident analysis pertaining to it, identification of safety-related structures, systems, and components, and other specific analysis if applicable (eg, criticality). The chapters covering safety

8. For example, foundation loading of the facility's building may be stated or assumed by the first phase covering exterior construction. This loading must be carried forward through all remaining phases so that nothing is placed in the building that would exceed that loading.

${ }^{9}$ - This means the 17 chapters of a Standard 3009-format SAR. 
Preparation of Phased and Merged SAR's for New DOE Nuclear Facilities

management programs, chapters 7 through 17 , as well as chapter 1 (Site

Description) generally are not strongly dependent on facility design and thus do not have to be provided until the final phase of the SAR, unless they drive specific design requirements.

Preparation and approval of any SAR phase will require a certain minimum amount of time. This minimum time has an important consequence. Because the SAR preparation and approval time can only be compressed so much, there is a maximum number of phases into which the SAR work could be divided beyond which it is practically impossible to accelerate the schedule. (To see the point. visualize the SAR in Figure Two broken into eight phases instead of four.) Beyond that maximum number of phases, a phased SAR cannot accelerate the schedule and will in fact delay it. This maximum number of phases is site and project dependent. ${ }^{10}$

If the phased SAR is also merged, then preparation of the SAR will take longer than either a PSAR or FSAR alone. This will likely extend $\Delta T_{\phi}$ and thereby make acceleration of the project schedule that much harder. Deciding to phase and merge a SAR therefore requires careful deliberation.

Given the number of SAR reviews and approvals, the safety analysis expenditure will be much higher with a phased SAR than for a conventional PSAR/FSAR preparation. As with a merged SAR, the manager must focus on saving time and make his decision accordingly.

10. As an approximation only, in order to accelerate the schedule, the following must be true:

$\sum^{n}\left(T_{\text {Prep }}+T_{\text {App }{ }^{\prime 1}}\right)-\left[n\left(T^{\prime}{ }_{\text {Prep }}+T^{\prime}{ }_{\text {App }{ }^{\prime 1}}\right)\right]>F_{\text {Tptal }}$. where $n$ is number of SAR phases: $T_{\text {Prepp/App:i }}$ is the time to prepare or approve each phase: $T^{\prime}{ }_{\text {prep } \angle A p p ' 1}$ ' 1 s the minimum time to prepare or approve each phase. and $F_{\text {Total }}$ is the total schedule float for SAR work. 
Preparation of Phased and Merged SAR's for New DOE Nuclear Facilities

\section{Success Factors:}

Success factors for using a phased SAR are somewhat different from a merged SAR. Preparing a phased SAR for a project will likely be successful if DOE is certain that:

1. the $A / E$ also prepares the safety analysis:

2. the $A / E$ has excellent control over scheduling and coordinating construction work and work crews. This is particularly important if the project is fast-track:

3. the $A / E$ has an excellent configuration management program to control design changes and an excellent design review process:

4. all project requirements have been clearly identified before start of design and are smoothly passed down through management and engineering levels to the construction crews in the field.

5. the contractor has excellent safety analysis skills in which DOE has justifiably full confidence based on historical experience.

Conclusion:

A phased SAR will not necessarily save time or money. As with merged SAR's, a phased SAR appears best suited for small, relatively simple facilities involving low to moderate radiological and toxicological hazards.

\section{Minimizing DOE's Risk:}

DOE's exposure to an inferior merged or phased SAR is minimized by performing a detailed and disciplined SAR review. Such a review requires selection of a particularly well-qualified review team using recognized experts. A successful review will identify any significant deficiencies in 
the SAR. The following review areas are crucial: design codes and standards (eg, selection of ASME, ANSI, ACI codes for the facility); radiation protection; seismic analysis; criticality analysis including expert knowledge of $M C N P^{11}$; safety analysis, including selection of safety equipment and accident evaluation: and human factors.

Once committed to by the project manager, it is extremely difficult to back out of a merged or phased SAR preparation. The decision to prepare a merged or phased SAR cannot be easily undone and a subsequent decision to do so will probably seriously delay the project's completion. well beyond any other delays. Because it is made at the outset of the project. cannot be undone later, and the down side to a wrong choice is very steep. the decision to prepare a merged and/or phased SAR must receive the greatest deliberate attention and scrutiny by DOE.

A DOE site should strongly reconsider a decision to prepare a phased or merged SAR for a project managed by a "M/I" contractor ${ }^{12}$ in which different sub-contractors perform major pieces of the work (eg. safety analysis. construction, and design); project requirements are new or unprecedented within the DOE complex: historical safety analyses have been only fair (or worse): the contractor has only fair configuration management and design review programs: or the $A / E$ is not the same contractor as the safety analyst.

11. Monte Carlo Neutron-Photon (Particle)

12. "Management and Integration" contractor, in which one contractor coordinates and manages field work actually done by a corp of smaller sub-contractors reporting to it. The opposite is the "Management and Operation" (M/O) contractor in which a single contractor does all work. 


\section{Application of Merged and Phased SAR's at a Major DOE Project:}

The Spent Nuclear Fuels Project (SNFP) at the Hanford site in Washington state is charged with moving to semi-permanent storage 2.100 metric tons of spent nuclear fuel elements left over from plutonium production. Two new facilities, the Cold Vacuum Drying Facility (CVDF) and the Canister Storage Building (CSB) are in final construction. The basic operation is shown in Figure Three. The SNFP chose to prepare the project's SAR's in phases and to merge the preliminary and final safety analysis reports into a single SAR (ie. a phased/merged SAR).

Note the sequence of operations and the processing of the fuel elements from one facility to another: $K$ Basins to the CVDF, the CVDF to the CSB. Each successive facility thus depends on and is coupled to the processing performed in the preceding facility. Therefore, the safety of the CVDF depends on the $K$ Basin performing its operations in a manner consistent with the assumptions and conditions assumed by the CVDF safety analysis. Similarly, the safety of the CSB rests on the CVDF performance. Coordination of the safety analyses is essential between the three facilities. Because the A/E for each facility was different, coordination of the assumptions employed by the three SAR's proved to be difficult.

DOE made a crucial decision at the start to manage the SNFP as "fast-track"--ie, design, procurement, safety analysis, and construction moved in parallel with each other. The SNFP found that field (construction) work can be done the quickest, followed by design work, followed by safety analysis and approval. Because field work could be done faster than safety analysis, SAR work quickly lagged construction and design, which, as the project was fast-track, were not locked in series and therefore moved ahead of the SAR 
work. As a result, when safety analysis caught up with design and/or construction, changes (backfits) often had to be made.

The SNFP also implemented a policy of "NRC equivalency" with the goal of achieving a rigor of safety analysis equivalent to that of an NRC-licensed fuel processing and storage facility. The novel (and unprecedented) use of "NRC equivalency" added further complexity and coordination difficulties. ${ }^{13}$

The $A / E$ contractor and construction contractor at each facility were not the same. The contractor performing the safety analys is was different from the $A / E$. Sub-contractors separate from the safety analysts performed the detailed $A / E$ design work.

Managing the project as a fast-track created numerous problems. Field work and procurement proceeded ahead of safety analysis. Design changes were made to the facility described in approved blocks of the SAR, which required re-analysis of the affected portions. For various reasons, DOE found the phased SAR to be deficient, which extended the approval time in order to correct the errors. Because of this, approval of the SAR phases lagged behind construction even more. This maximized $\Delta \mathrm{T}_{\phi}$. Eventually SAR work became critical path for the CVDF and CSB.

The lack of approved phases of the SAR spilled over into equipment procurements, which lacked approved standards and requirements based on a SAR. Pressure to maintain schedule resulted in extensive use of the "escape clause" provision in DOE Order 5480.23, allowing equipment to be procured or

13. The paper "Application of 'Nuclear Regulatory Commission Regulation Equivalency' to Construction of New DOE Nuclear Facilities". by G. E. Bishop and Gregory Z. Morgan. presented at the June. 1999 SAWG meeting in Portland, Oregon, extensively discussed SNFP's use of NRC regulations. 
construction to proceed without an approved safety analysis. ${ }^{14}$ Procurement and construction of substantial portions of both the CVDF and CSB were done without any SAR whatsoever.

When the SAR's caught up to design and procurement, errors were found which required time ( $T_{\text {Rework }}$ in Figure One) and resources to resolve. Resolving these deficiencies diverted project time, funds, and attention from pressing on-going field work, resulting in yet further delay to the project's critical-path. This feedback effect overwhelmed whatever acceleration might have been possible using a merged/phased SAR. The SNFP found no clear advantage to using either a merged or phased SAR. Project schedule was not accelerated.

Significant Problems Encountered in Preparing Merged/Phased SAR's:

Phased SAR Difficulties:

System descriptions for the CVDF did not match actual as-built work. resulting in rejection of one CVDF SAR phase. System descriptions were often vague simply because parallel design and procurement work was not complete and the analyst did not know what kind of system was to be used in the facility. Design specifications did not always reflect design requirements, resulting in subsequent exemption requests to those requirements or some design changes. Analysis techniques, particularly for load drops in the $K$ Basins and the CSB. were incorrect or modeled incorrectly. Analyses were not always adequately

\footnotetext{
14. Paragraph 9.a.(1) of DOE Order 5480.23 states in part: "DOE may authorize, in writing. limited activities [procurement, construction, pre-operational testing] without approval of a PSAR." "Limited activities" is not defined.
} 
Preparation of Phased and Merged SAR's for New DOE Nuclear Facilities explained. Thus, quality of the phased SAR submissions was not always adequate.

The root cause of poor quality was failure at the early stages of project planning to recognize the level of effort that a phased/merged SAR preparation would need. No Hanford facility had ever prepared either a merged or phased SAR. There was no experience base. Simply put. the scope attendant with preparing a phased PSAR/FSAR for a major project like the SNFP was not appreciated or understood. The earlier SAR submissions tended to be of a PSAR-level detail. rather than the more detailed, specific FSAR-level needed for a merged SAR. The vital need to coordinate design, procurement, and safety analysis at the pace of a major fast-track project using a multitude of sub-contractors overwhelmed contractor (and DOE) capabilities. Funding for safety analysis remained inadequate until the latter stages of the project when SAR approval became critical path. Underfunding reduced the means to resolve the quality problem. Relentless schedule pressure also contributed significantly to the problem. Analysts were overloaded trying to prepare blocks of SAR chapters in FSAR-level detail in parallel with designs that had not been completed, a task that had never before been attempted and is obviousiy extremely difficult. DOE Oversight and Approval Difficulties:

The contractor originally recommended that a single merged SAR be prepared for the SNFP. To reduce its risk. DOE mandated that a merged SAR be prepared in phases for the project.

DOE created a team of experts (about twenty) in various SAR technical areas (structural, radiological, criticality, etc) to review the SAR submissions. Generally, a reviewer would review only selected chapters or 
Preparation of Phased and Merged SAR's for New DOE Nuclear Facilities

sections of chapters. A few reviewers examined the entire SAR submission.

Except for the tank farms. Hanford had not commissioned such a review team in any previous SAR work.

DOE review generated over 3,200 comments on the CSB and CVDF merged/phased SAR's. The safety analysis was found to be both overly conservative in some areas and under-conservative in other ways. Some reviewers believed the safety analysis simply justified the chosen design. rather than establish a safety envelope which the design then had to meet. This belief is consistent with a fast-track project. The number and extent of the comments seemed to surprise and startle the contractor. Some sub-contractor preparers were clearly not used to the scrutiny of review that they received. Friction developed at times which required management intervention to amicably resolve. Some DOE reviewers felt they "reviewed the quality" into the SAR submissions.

Despite repeated requests to do so, the contractor never shared preliminary (ie, unissued unofficial) safety analysis with the DOE review team. Team members believed this unnecessarily caused longer reviews when the analysis came over formally from the contractor. Lack of sharing probably reflects an adversarial type of relation between the contractor and DOE.

However, from the contractor's perspective. DOE sometimes appeared indecisive and befuddled in its direction. DOE appeared at times overly obsequious to external influences, such as oversight agencies (the DNFSB). Decisions were later changed to achieve political ends--eg. appease an external influence.

Difficulties Implementing Program Requirements: 
Preparation of Phased and Merged SAR's for New DOE Nuclear Facilities

The SNFP applied the standard spectrum of DOE order requirements (eg. $6430.1 \mathrm{~A}, 5480.23,4700.1$, etc) via the contract Standards/Requirements Identification Documents. In addition, the SNFP also adopted a set of requirements from the Nuclear Regulatory Commission, termed hereafter as NRC-equivalence requirements. This effort was unique to the SNFP and unprecedented within the DOE complex. The A/E did not completely incorporate requirements from either set (DOE or NRC) into the facility design. Discovery of these oversights caused delay in approving the applicable SAR phase.

\section{Examples:}

Canister Storage Building Structural Design:

The SNFP adopted NRC-equivalent criteria for natural hazards (eg. tornadoes) to the design of the CSB. ${ }^{15}$ The NRC criteria are more rigorous and thus require a stronger building than the natural hazards criteria previously used at Hanford. The contractor did not impose the NRC requirements during design of the building. Because the CSB construction cost estimate had been estimated using the older site criteria, applying the NRC natural hazards criteria resulted in a marked increase in the building's cost. Multi-Canister Overpack Handling Machine:

The contractor did not pass on separation criteria for safety-class electrical equipment, another NRC-equivalence requirement. DOE procured the Handling Machine using the escape clause to Order 5480.23 and at that time had no safety analysis

15. These are contained in Reg Guide 1.76, "Design Basis Tornado for Nuclear Power Plants". SECY-93-087, "Policy. Technical, and Licensing Issues Pertaining to Evolutionary and Advanced Light-Water Reactor (ALWR) Designs", and NUREG/CR-4461, "Tornado Climatology of the Contiguous US". 
for the Machine. This deficiency delayed approval of the

completed CSB SAR and required modification of the Handling

Machine itself.

Canister Storage Building Storage Tube Material:

Prior to approval of a SAR and agreement on the correct design code, the contractor specified the storage tube material to API $5 \mathrm{~L}$ standards and issued a procurement order. Subsequent safety analysis showed that API $5 \mathrm{~L}$ was not an appropriate code. As a result, the SNFP devoted extensive time and resources demonstrating that the procured tube material met safety requirements. Eventually, the material was accepted for use.

\section{Enabling Assumptions:}

Safety analysis for the next phase of construction was often incomplete prior to approving that next phase's SAR. This left gaps in the SAR. In addition, design was also not always complete for the next phase, either. The SNFP created "enabling assumptions" (EA's) to carry a specific commitment or restriction assumed by the previous SAR phase forward into subsequent phases. The EA could be a key safety assumption (eg. area of a fuel assembly exposed to air or water), assumptions on design, assumptions on modeling techniques. etc. These assumptions were design commitments as we11. EA's are inevitable when using a phased SAR. Any phased SAR can be expected to generate a certain number of EA's. It is impossible to predict a "proper" number for a project.

The SNFP generated over 80 EA's. The number of SNFP EA's may appear (and likely were) excessive. Tracking such a large number through the process proved burdensome and the SNFP created a special program to track and close 
them. To facilitate closure of the EA. the SNFP prepared a plan that identified the SAR phase in which a specific EA would be closed. Unfortunately, this plan was not implemented after being issued.

Closing the EA's proved difficult. Closure of a safety (as opposed to a design) EA required preparation of a safety analysis sufficient to resolve the associated issue. Development of this analysis lagged, due to priority conflict and limited funding. Because some EA's, eg, fuel surface area, had enormous impact on the project design. DOE occasionally took the lead to close an EA using a panel of technical experts independent of the contractor. Use of this panel created some rancor with the contractor. However, the panel did allow timely and successful closure of several critical EA's which vastly simplified the project's final design.

In retrospect, the large number of SNFP EA's reflected the insufficient funding and priority given to safety analysis during construction. In effect, issues behind the $E A^{\prime}$ 's were allowed to drag on without resolution while construction issues received the greater attention. As a result, most of the $E A$ 's were not closed until submission of the final (completed) facility SAR. Because many of the EA's were safety assumptions, closing them required safety analysis which, of course, DOE had not previously seen.

Closing the EA's en masse in the final SAR resulted in the most detailed and rigorous review of SAR's that DOE gave to the project. This intense review thus came at precisely the worst possible time, after most of construction was finished, requiring rework and backfits to correct errors, while the contractor was under great pressure to wrap up field work to maintain schedule. The net result was the creation of substantial friction 
and animosity between the contractor and DOE at a crucial juncture in the project, to no good end.

\section{Configuration Management and Design Review:}

Configuration management (control, dissemination, and coordination of design changes) is a key feature to prepare successful phased SAR's. The contractor's configuration management program is probably as good as any other in the DOE complex. Unfortunately, the contractor's program could not keep up with the pace of fast-track construction. Design descriptions in the SAR phases were often incorrect. SAR's contained incorrect or substantially incomplete information. Design changes were made to approved phases of SAR's thus requiring a second review of those SAR phases (basically re-reviewing selected issues thought to have been closed). This confused and extended review of the later SAR phases.

The contractor's design review process did not identify some noncompliances to design requirements (examples provided above). The root cause of this deficiency is not known. Schedule pressures likely significantly contributed to inadequate design reviews.

\section{NRC Equivalency:}

NRC requirements were applied to the project in two ways: as direct requirements on design and as requirements on safety anaiysis preparation and review. Detailed assessment of the NRC equivalence program has been discussed elsewhere and will not be repeated here. ${ }^{13}$ The SNFP found that implementing NRC requirements on top of DOE requirements is often contentious and costly. both in terms of money and schedule. Other than public perception, obvious benefit of such a program to facility design is unclear and no major 

improvement in over-all project safety was obvious by implementing NRC requirements above and beyond those already required by the DOE. In a like manner, other than what public perception there may be, no obvious improvement in the quality of preparation or review of the project SAR's was evident from applying NRC standards to the SAR preparation or review.

This suggests that the key to safe facility construction lies with rigorous and competent implementation of sound safety requirements, no matter their source, rather than the pedigree of the requirements themselves. Quality SAR's are similarly the product of competent teams of SAR preparers and reviewers, and not any particular set of review requirements.

\section{Impact of SAR Rejections and the Project Response:}

DOE rejected a SAR phase three times due to inadequacies (twice for the (VDF, once for the MCO). Rejecting a SAR did nothing to correct the underiying systematic deficiencies causing the submissions problems.

SAR rejection also created an unanticipated dilemma. As previously discussed, delay in approval of a SAR phase caused construction delay and thereby delayed the project even more. The SNFP found that such delays quickly "pancaked" one on top of another, one delay causing another delay downstream, until SAR preparation became almost entirely critical-path. In effect this maximized $\Delta T_{\phi}$ in Figure Two. The project schedule slipped badly which brought even more pressure on SAR preparation. Haste caused more errors in the SAR submissions to DOE, which caused yet more delay in approval of those phases. And so it went, one delay compounding another.

Teams were commissioned to determine the underlying problems causing SAR rejections and the high number of review comments. Little was ever done with 
Preparation of Phased and Merged SAR's for New DOE Nuclear Facilities -24the resulting recommendations and the SAR preparation process was never

substantially changed. Management initiatives to improve SAR submissions were ineffectual.

The major effect on the project was a vastiy increased expenditure on safety analyșis, far beyond original estimates. Funding for SAR preparation more than tripled to more than $\$ 10$ million.

\section{Conclusions:}

The SNFP gained no clear benefit by using a merged/phased SAR. The project schedule was not accelerated.

The following are other specific conclusions:

1. Do not expect to save project money preparing merged/phased SAR's. It may be possible to save schedule time. Cost savings witl either be trivia1, or negative--ie, require more expenditure than not preparing merged/phased SAR's.

2. Preparing a phased SAR for a moderately or highly complicated facility will tax the best of contractors. Excellent configuration control and design review will be needed. Excellent coordination between safety analysis and design will be needed.

3. Attempting both merged and phased SAR's for the same facility is too difficult and should not be attempted. except possibly for extremely simple projects.

4. Complete the design of the next phase of a SAR prior to approving that phase's SAR (and ensure the SAR matches the design). Reliance on 

enabling assumptions (or equivalent) to track unfinished design commitments will be unexpectedly difficult.

5. A merged SAR is not feasible for a fast-track project.

6. Use of the "escape clause" to DOE Order 5480.23 to allow procurement or work without an approved SAR should not be done.

7. For moderate or high-hazard facilities, safety analysis will require the greatest amount of schedule time. Design work requires less time. Construction work. perhaps surprisingly, requires the least amount of time.

8. The DOE SAR review team must be composed of recognized technical experts and be particularly strong in construction, seismic, and design codes, and human factors.

9. Generation of a significant number of EA's in a phased SAR is a certain sign that approval of the final (completed) SAR will be difficult and that not enough attention is being given to closure of safety analysis issues.

10. When making project decisions, vacillation is a vice; steadfastness, a virtue.

11. Use of expert panels independent of the contractor (ie, funded through DOE alone) can facilitate timely and reasonable closure of project technical or safety issues. 


\section{Recommendations:}

1. Do not prepare a merged or phased SAR for multiple facilities in which the safety basis of one facility is strongly dependent on the operation (output) of another facility.

2. Do not prepare a merged or phased SAR for multiple facilities designed/constructed by different contractors, or in which major portions of a large and complex facility are designed/constructed by different contractors.

3. Do not prepare a merged SAR for "fast-track" projects.

4. Do not prepare merged and phased SAR's together for a project. Do either a phased or merged SAR, alone. Phased or merged SAR's are best suited to simple, low-hazard (ie, hazard category three) facilities.

5. Do not allow most EA's to be closed in the final (completed) SAR of a phased SAR preparation.

6. Do keep preparation of a 11 portions (chapters) of the merged or phased SAR under a single contractor who is preferably the facility's A/E design contractor.

7. Do keep the facility's A/E the same as the construction contractor, unless management can safely state that its configuration management program is nothing short of excellent.

8. Do start DOE review of the merged or phased SAR well ahead of (three months, minimum) the required approval date to support the project schedule.

9. Do ensure that DOE reviewers are highly qualified. well beyond what is typically considered adequate for traditional (non-merged/phased) SAR reviews. 
Preparation of Phased and Merged SAR's for New DOE Nuclear Facilities

$-27-$

10. Do ensure for phased SAR's that the DOE review is completed before that applicable portion of the facility's design is released to construction.

11. Do employ expert panels independent of the contractor as needed to assist closure of project technical issues or safety analysis enabling assumptions. 


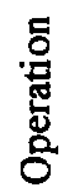

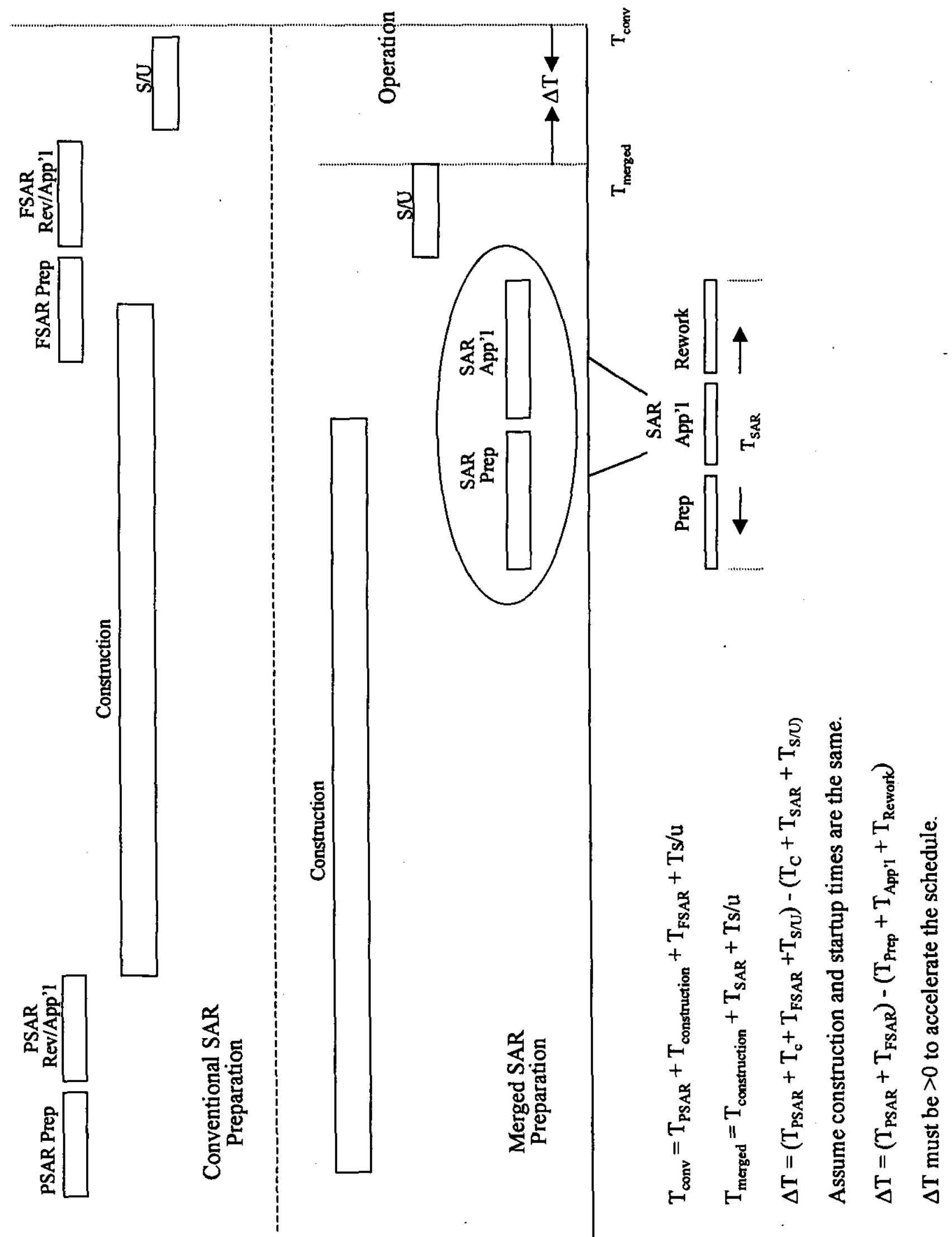




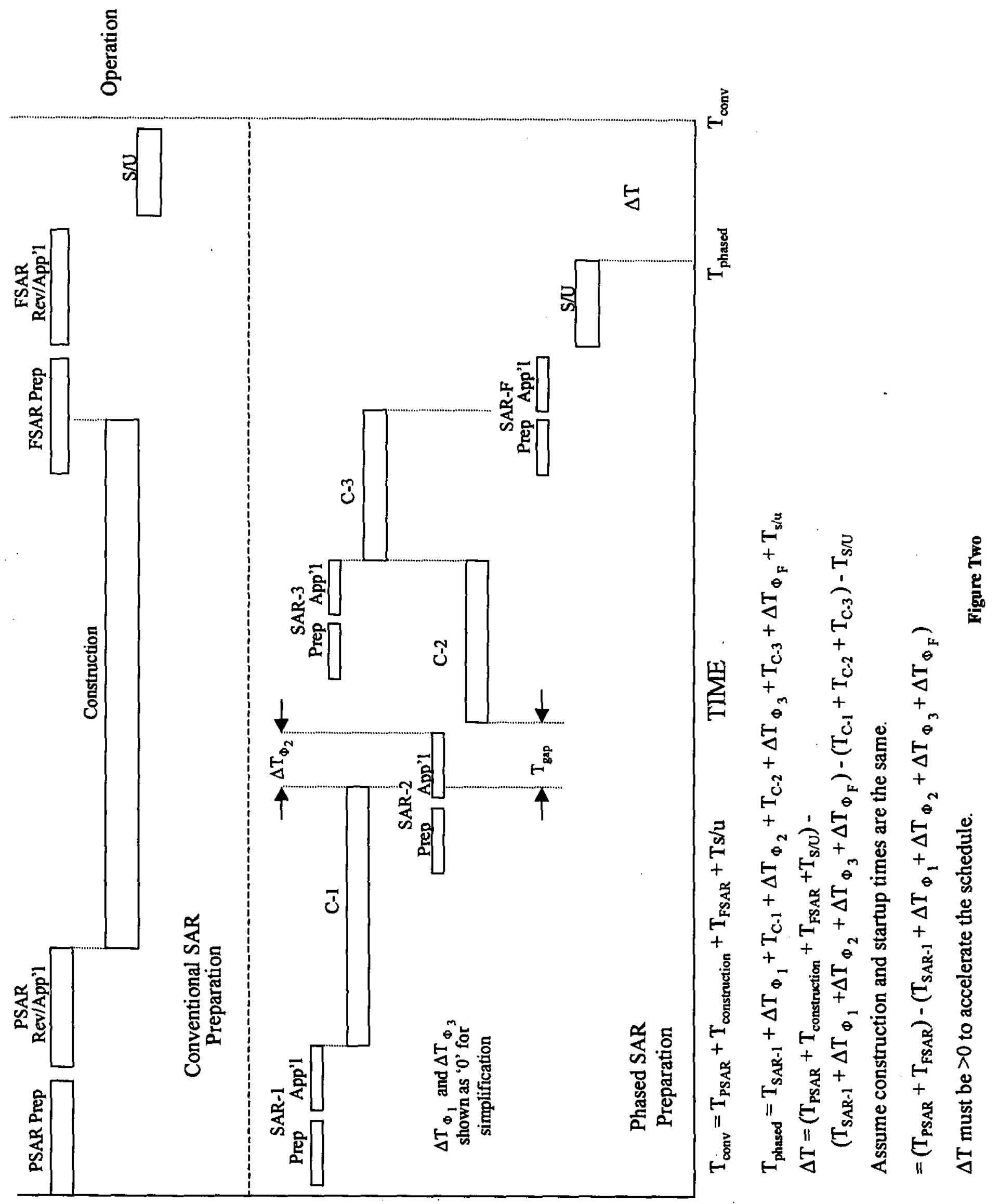




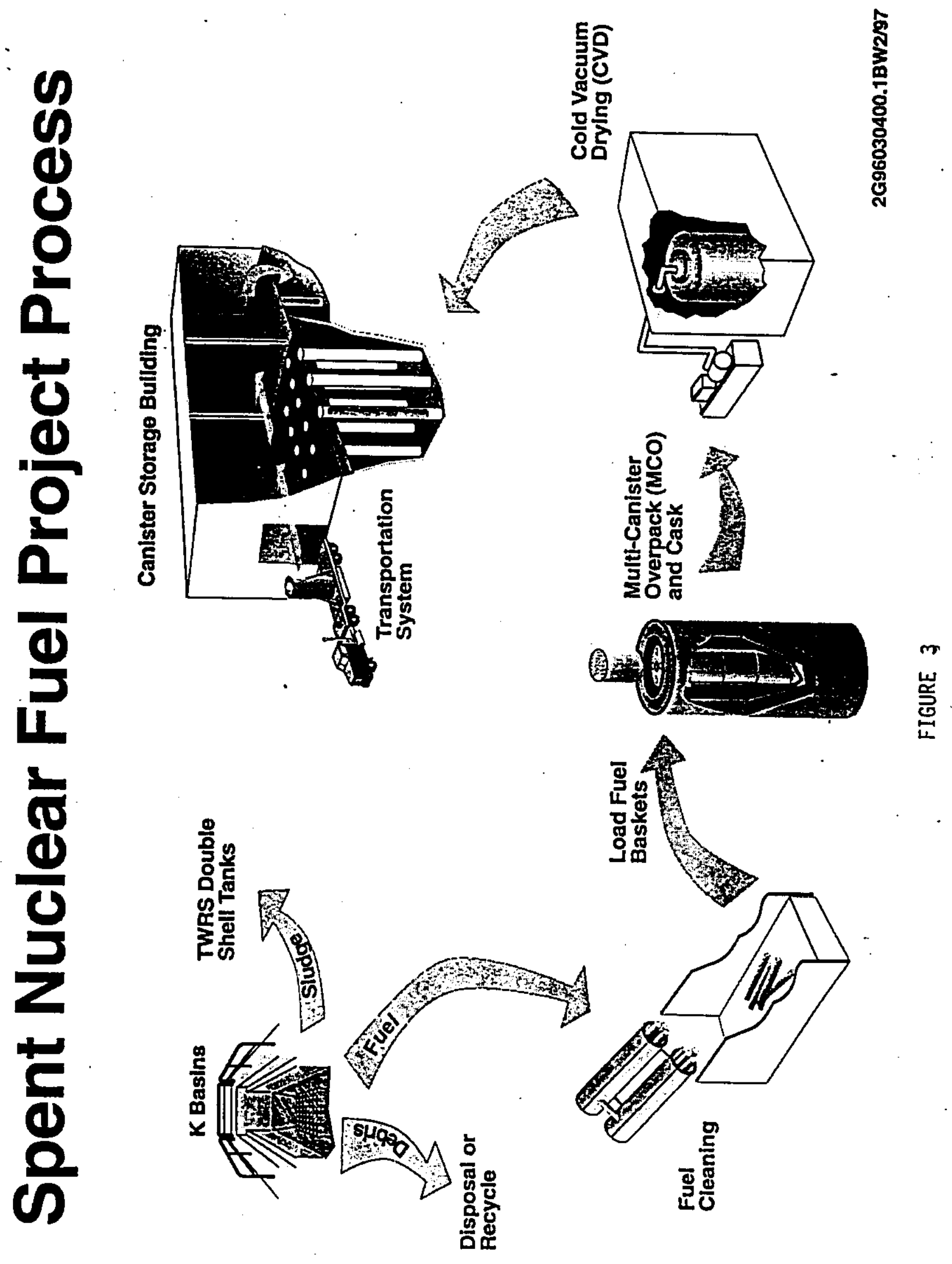

